\title{
Failure Analysis of Queensland Payroll System
}

\author{
Zhu Ziyan ${ }^{1, *}$ \\ ${ }^{1}$ Engineering school, The Uuiversity of Sydney, Camperdown, Sydney, NSW, Australia, 2006 \\ *Corresponding author. Email: donghuangxun@gmail.com
}

\begin{abstract}
Queensland government tried to innovate and improve the payroll system, but there were many loopholes in the operation of the project. In fact, from 2015 to 2020, about a quarter of the state's public health workers have to bear outstanding debts due to the Queensland Government's overpayment of about $\$ 110$ million (Australian dollars) to the state's health workers [5]. This paper introduces the problems existing in Queensland's wage system, evaluates and analyses the innovation process of the system, and completes the whole research process by investigating a series of documents issued by Queensland government, using the method of qualitative analysis and case study. Through the above research, this paper puts forward corresponding solutions to the problems of Queensland government payroll. On the one hand, in the part of innovation and improvement, this paper puts forward the solutions of management and customers; On the other hand, this paper also puts forward a series of reform measures for the reform of the leadership system.
\end{abstract}

Keywords: Innovation, Queensland payroll system, Agile, Project management

\section{INTRODUCTION}

Nowadays, more and more organizations and departments begin to study how to improve the efficiency of the medical industry and save money. To solve this problem, Thite and Sandhu (2014) point out that redesign of business processes and reform and deployment of new technology is a good solution [8]. However, Bohmer (2010) believes that in a large and complex medical system, it is difficult to achieve the above changes [2]. In view of the above conclusions, Fisher and Howell (2004) show that when testing the total failure rate of a new IT system, the total failure rate is close to $50 \%$. This means that nearly half of the systems cannot meet the requirements of the project, which may lead to the failure of the project. Thite and Sandhu (2014) believe that such a high failure rate is not entirely due to the technical limitations of the system itself. The lack of coordination means and rigid management system for innovation in the organization itself will lead to the failure of the IT system to achieve all or most of the goals of the project [8].

Due to the above reasons, as one of the earliest business processes implemented in the work, payroll processing technology also faces many problems (Thite et al, 2012) [7]. Queensland Department of health tried to introduce a new payroll system, but it soon failed.
Horn (2020) points out that between 2015 and 2020, the Queensland Department of Health paid about \$110 million (Australian dollars) to health workers in the state, and nearly a quarter of health workers in the state have outstanding debts to repay [5].

Based on the case study of the innovation of the payroll system in the Queensland health system, this paper attempts to evaluate the payroll calculation system and the management system, and finds out the problems in the innovation and other aspects of the system according to the evaluation results, and puts forward the corresponding solutions.

The main research significance of this paper is to find some common problems that may appear in the process of large-scale system innovation, and how these common problems hinder the implementation of innovation and put forward corresponding solutions.

\section{METHOD}

Because this paper mainly uses a case study to analyse the data, so qualitative analysis is a more appropriate research method. Flick (2007) believes that qualitative analysis can usually be used as a label for a series of social science research methods [4]. The qualitative analysis mainly takes the concept of research as the research basis, takes the text as the demonstration 
material, and focuses on the practical results, viewpoints and theories of the research object. Therefore, the research materials of this paper are mainly from the public literature published by the Queensland government. With the help of these public documents and published reports, this paper also combines the research methods of case study to help complete the qualitative analysis.

The outbreak of the payroll problem was earlier than in 2015. In fact, in 2010, the Queensland government published some investigation reports on the work system. The main research materials of this paper also come from these investigation reports.

\section{ANALYSIS}

The following parts will evaluate and analyse the reform of the payroll system and the leadership system.

\subsection{The reform of the payroll system}

The Queensland Health work system report submitted by the Queensland auditor general in 2010 shows that the Queensland payroll system first used the method of printing payroll [1]. About 40000 e-mails and faxes are received by production personnel on each payday [8]. In view of this situation, Thite and Sandhu (2014) believe that it is inevitable for staff to have problems when dealing with such a large number of wage issues [8]. Therefore, every time after the completion of salary payment, about 15000 modifications and adjustments need to be made [8]. In this case, the Queensland government chose a new payroll system and introduced a new computing system. One of the systems implemented by the Queensland government is called SAP finance. IBM is the main contractor responsible for the management and implementation of the payroll and scheduling system. Chen and Sawhney (2010) point out 12 types of innovation to form innovation radar, namely product, platform, solution, value capture, management, process, customer, communication, interface, supply chain, channel and ecosystem innovation [3]. According to the results of the research report, the main value of the calculation system of the payroll system is reflected in the product, that is, replacing and upgrading the original payroll system, providing a more modern way of processing.

But this innovation also has a very big problem, the first is from the management. Queensland Auditor General (2010) points out that the Queensland government required IBM to replace the original payroll system through the model of SAP human resources department housing system, and complete the replacement of the whole system through a few necessary changes [1]. However. The scope of the project and the complexity of the project implementation are seriously underestimated. Due to this negligence, the actual cost of the project is far greater than the budget cost of the project [1]. The second is from the user side. Before the payroll system went online, IBM organized user experience. However, due to the continuous change requests (Mainly from the project requirements that were not elaborated and agreed upon in the project planning stage), only $60 \%$ of the functions of the new system were tested in the test process, which could not meet the final test requirements. At the same time, $10 \%$ of the project staff are selected as users for the system experience, but the number of users is not enough to meet the needs of the number of test samples of the new payroll system, which cannot ensure the accuracy of the test [1]

\subsection{Project leadership system}

The key departments of the project, including IBM, have the problem of management structure confusion. Specifically, there are no clear provisions on the roles, authorities, responsibilities and division of labour of all parties. At the same time, in the whole payroll system reform project, the leadership did not require a complete project management plan. Many important parts of the project, such as project budget management and project risk management, have not made a more detailed and feasible plan. In the project budget management, there is no corresponding forecast solution for the cost overrun problem, and there is no appropriate planning for the cost needs of stakeholders. In risk management, although the project team conducted a comprehensive risk assessment before the operation of the payroll system, the project did not choose a quantitative assessment method to manage the risk, nor did it propose a plan for risk mitigation measures. From these perspectives, there are undoubtedly very serious mistakes in the leadership system of the whole project.

\section{RECOMMENDATION}

According to the above analysis, this paper can draw the following recommendations:

\subsection{Improve the payroll system with an agile method}

Rigby et al (2015) propose that agile, as a relatively perfect system, is very effective in helping to overcome the problems of innovation [6]. In fact, agile method was first used in software development projects. This method increased the average success rate of software development projects from $11 \%$ to $39 \%$, which increased the success rate by more than three times (Rigby et al., 2015). Compared with traditional methods, agile methods can provide about 6 times success rate when applied to larger and complex 
projects [6]. For this reason, this paper will try to use agile method to improve the payroll system.

The principle of agile mainly focuses on the team. We need to build a small-scale, self-management and project focused team according to the needs of the project. All members of the team are generally from the business department that the project needs. Team members need to allocate time and tasks to different key stakeholders, build a series of tasks to be completed according to the project requirements, and the project manager needs to continuously update these tasks according to the stakeholders and the financial status of the project. The most important thing of an agile team is that team work should not be interfered by non-project factors, and each team member is the owner of the project, and work together to complete the project.

This process can be intuitively reflected through the following flow chart:
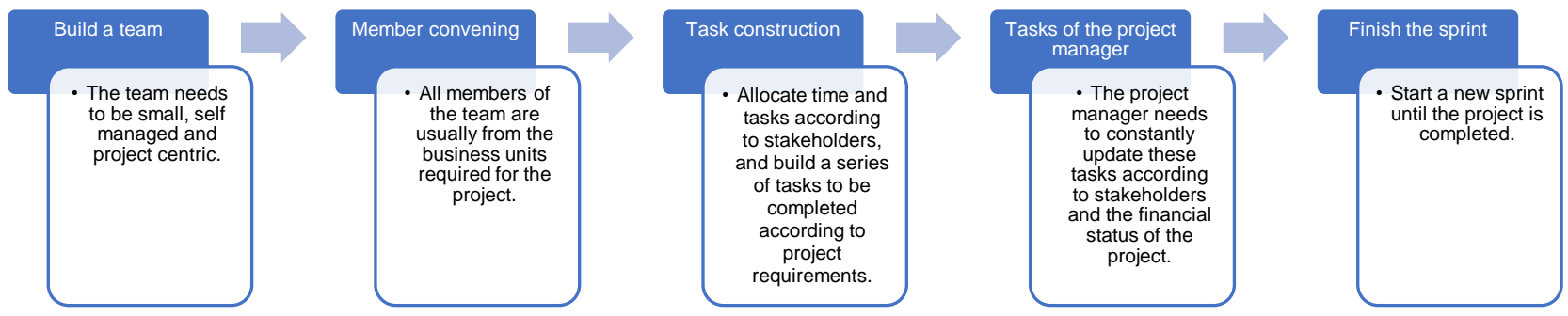

Figure 1: Agile process

In view of the improvement of the payroll system, IBM can consider re-planning and re-designing the payroll system to determine a more accurate project scope, rather than copying other projects. After the scope of the project is determined, the main task of the project can be considered to be disassembled into several small modules, and assigned to each small module to complete the task and work period, and the corresponding work template can be built in a short cycle called sprint. It is worth noting that, due to the complexity and relevance of the payroll system itself, the use of agile methods can maximize the transparency of project implementation, that is, the work results of various departments can be shared to avoid management mistakes. In addition, according to the agile method model, the project team needs to hold a simple meeting every day to review yesterday's progress and challenges. This step can help the project team solve the impact of frequent change requests.

At the same time, the agile method can solve the user problems in the payroll system. As mentioned before, the testing process of the system cannot meet the complete needs of users, and agile methods can continuously generate new small tests to be completed by cutting the tasks. These tests are relatively uncomplicated and do not require a lot of human resources. When the user test is satisfied, the project will immediately move to the next link. The completed tests can meet the needs of users as much as possible, and the tests that are still in progress can also be changed quickly with the help of agile working characteristics. When the project is completed, the whole test activity can also get very complete test results.

\subsection{Improve the leadership system with the knowledge of project management}

First of all, the leadership system needs to be changed accordingly. The project manager who has the leadership over the project will allocate the roles, tasks and responsibilities of each department of the project, so as to avoid confusion in the process of project implementation. Secondly, the project needs to develop a complete project management plan, including the budget supervision and management mechanism and risk management mechanism, to make relatively perfect planning for the project, rather than using other completed project models. Finally, for project leaders, they need to improve the following five qualities to improve their own leadership (Toussaint et al, 2017): Wiliness, leaders need to actively adapt and be familiar with innovation, and reflect on completed projects; Humility, in most projects, team members from different fields often have more professional skills than leaders, and leaders need to respect and understand these skills; Curiosity, leaders need to always keep the spirit of exploration, understand the problems in the project, and then propose corresponding solutions; Perseverance, in dealing with more complex projects, leaders need to complete more tasks, too much data, frequent change requests will increase the workload of leaders, which requires leaders to adhere to complete the tasks they need to complete; Self-discipline, leaders need to strictly abide by the established project rules and regulations, and maintain the normal operation of the team [9].

\section{CONCLUSION}

Through the case study of the Queensland Health payroll system, this paper finds the reasons for the huge 
loopholes in the system. Firstly, in the part of innovation, due to the negligence of the Queensland government and IBM in management, the scope of the project and the complexity of project implementation are seriously underestimated, resulting in the actual cost of the project being far greater than the budget cost of the project. The second problem comes from the client. IBM cannot guarantee that the number of user test samples meets the demand. At the same time, due to continuous change requests, user testing cannot achieve the ideal test range. Secondly, there is a very serious management confusion in the key departments of the project. The management has neither clearly defined the roles, powers, responsibilities, and division of labour of all parties, nor formulated a relatively perfect project management plan.

Because of the above problems, this paper puts forward two solutions. First, the agile method model is used in the improvement process of the payroll system. After determining the project scope, the project team can divide the project into several sprint modules through the agile method, and make time planning and task arrangement respectively. At the same time, in order to solve frequent change requests, the project team needs to hold meetings every day according to the agile method to summarize and formulate new tasks. During the cutting process, the project team can test the completed modules to meet the needs of user testing. Secondly, the leadership system needs to be improved and a complete project management plan needs to be formulated. At the same time, the project leader needs to improve wiliness, humility, curiosity, perseverance, and self-discipline these five qualities to improve the leader's leadership ability [9].

\section{ACKNOWLEDGMENTS}

Thank Dr Sabine Ludewig very much for her knowledge of critical thinking, which plays an indispensable role in the construction of the whole article. Thank Dr. Karyne Ang and Catherine Graham very much. Their lectures on the relationship between people and leadership have answered many of my doubts. At the same time, I would like to thank Dr. Kishore Sengupta for his wonderful knowledge transfer in the field of innovation research. These contents constitute the main content of this article. I am also very grateful to other teachers and students who are willing to communicate with me about the knowledge involved in the article.

\section{REFERENCES}

[1]. AGQ (2010a). Report to Parliament No. 7 for 2010. Information Systems Governance and Control, Including the Queensland Health Implementation of Continuity Project. Auditor-General of Queensland. Queensland Audit Office, Brisbane, Australia.

http://www.qao.qld.gov.au/files/file/Reports/2010_ Report_No.7.pdf

AGQ (2010b). Report to Parliament No. 13 for 2010. Results of Audits at 31 October 2010. Auditor General of Queensland. Queensland Audit Office, Brisbane, Australia. http://www.qao.qld.gov.au/files/file/Reports/2010_ Report_No.13.pdf

[2]. Bohmer, R. (2010). Fixing healthcare on the frontlines, Harvard Business Review, 88 (4), 62-69.

[3]. Chen, J.Y., \& Sawhney, M. (2010). Defining and Measuring Business Innovation: The Innovation Radar. DOI:10.13140/RG.2.2.22863.07846

[4]. Flick, U. (2007). Designing qualitative research. Los Angeles, Calif.; London: SAGE

[5]. Horn, A. (2020). Ongoing Queensland Health payroll problems see staff overpaid by nearly $\$ 110 \mathrm{~m}$ since 2015. Australian Broadcasting Corporation news, Posted Friday 2 October 2020 at 3:30am, updated Friday 2 October 2020 at 5:01am

[6]. Rigby, D.K., Berez, S., Caimi, G., \& Noble, A. (2015). Agile innovation. Bain \& Company, 2015.

[7]. Thite, M., Kavanagh, M.J., \& Johnson, R. (2012), 'Evolution of Human Resource Management and Human Resource Information Systems: The Role of Information Technology', In Human Resource Information Systems: Basics, Applications \& Directions, ed., M. J. Kavanagh, M. Thite, R. Johnson. Thousand Oaks, CA: Sage.

[8]. Thite, M., \& Sandhu, K. (2014). Where is My Pay? Critical Success Factors of a Payroll System - A System Life Cycle Approach. Australasian Journal of Information Systems, 18(2).

[9]. Toussaint, J.S., \& Ehrlich, S.P. (2017). Five Changes Great Leaders Make to Develop an Improvement Culture. NEJM Catalyst, catalyst.nejm.org. 